\title{
A Comparative Analysis of Changes of Student's Attitude Before and After an International Virtual Learning Class
}

\author{
Yusuke Morita \\ Nagasaki University, \\ Faculty of Education \\ ymorita@net.nagasaki-u.ac.jp \\ Byungdug Jun \\ Nagasaki University, \\ Faculty of Education \\ bdjun@net.nagasaki-u.ac.jp \\ Kenji Watanabe \\ Saga University, \\ Faculty of Science and Engineering \\ watanabe@is.saga-u.ac.jp
}

\author{
Takashi Fujiki \\ Nagasaki University, \\ Faculty of Education \\ t-fijiki@net.nagasaki-u.ac.jp \\ Sangsoo Lee \\ Chonnam National University, \\ College of Education \\ soolee@jnu.ac.kr \\ Kohtaro Kamizono \\ Nagasaki University, \\ Faculty of Education \\ kamizono@net.nagasaki-u.ac.jp
}

\author{
Toshihiko Shimokawa \\ Kyushu Sangyo University, \\ Faculty of Information Science \\ toshi@is.kyusan-u.ac.jp
}

\author{
Daisuke Yagyu \\ Nagasaki University, \\ Information Processing Center \\ d-yagyu@net.nagasaki-u.ac.jp
}

\author{
Chiaki Nakamura \\ Nagasaki University, \\ Faculty of Education \\ sonny@i.edu.nagasaki-u.ac.jp
}

\begin{abstract}
The purpose of this study was to investigate the effects of international virtual learning classes. For the purpose, the class implemented using multipoint communication system which was constructed high quality video transfer systems on a cross-border infrastructure (gigabit bandwidth) between Japan to South Korea. In order to reveal the effects of the class, a questionnaire was composed of five categories; Consciousness to Foreign Countries, Nationality, Acquisition of View Point, Motivation, Recognition to the partner country. The results of $2 \times 2$ mixed two-way ANOVA showed differences of characteristics of two countries and changes of student's attitude. The results revealed that an international virtual learning class has a possibility to develop and enhance student's awareness of humanity and the world. Future implementation will depend on growth and sustenance of the international relationship for a prolonged period.
\end{abstract}

\section{Introduction}

It is important to develop and enhance student's view of the world. Recent years, school teachers can use a video chatting system easier than before. The communication tools, nevertheless, are not quite to implement a class. Morita et al. suggested a virtual classroom activity using a multipoint control unit with cellular phone [1]. The virtual learning class gave good effects for the students' attitude to the important intangible cultural heritage.

Accordingly, international virtual learning class in elementary or junior high schools using high quality video transfer system may be one of the solutions for the global understandings.

An effective international virtual learning class needs a high quality video transfer system. DVTS (Digital Video Transport System) is one of the most useful tools for distance communication for sending and receiving Digital Video streams through IEEE1394. The use of high performance computers connected to a gigabit network is recommended as a 
tradeoff exists between video quality and the transmission bandwidth required for the transfer system [2]. Morita et al. suggested that virtual learning classroom visitations and distance evaluation meetings using DVTS were useful to train student teachers [3]. On the other hand, Watanabe et al. developed a remote blackboard presentation system which worked with the DVTS [4].

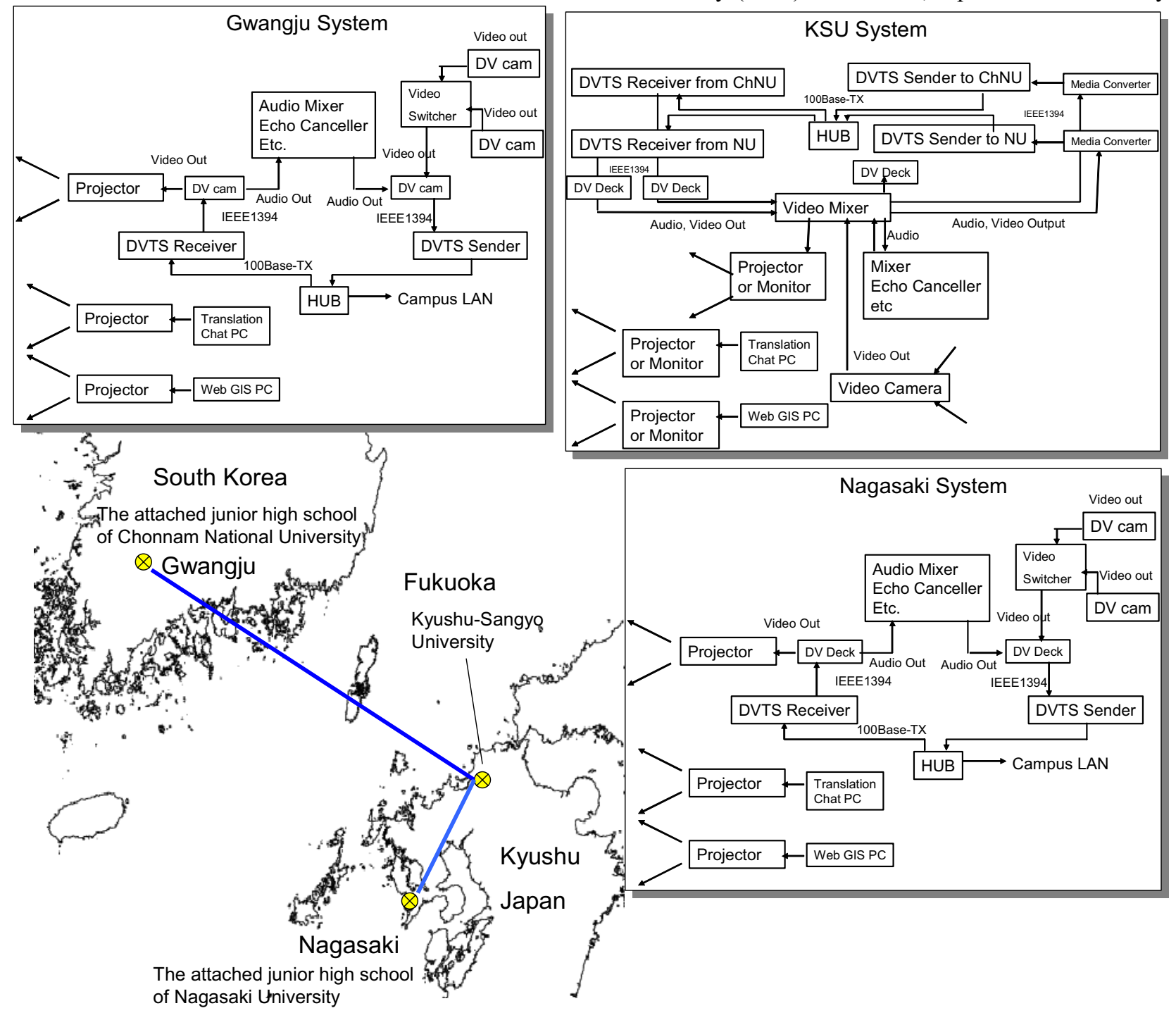

Figure 1: Network and systems

The purpose of this study was to investigate the effects of an international virtual learning class using DVTS.

\section{International Virtual Learning Class}

\subsection{Network System}

Figure 1 shows the location of the three points and video/audio systems configuration of the international virtual learning class. Teachers (who are the professors of Nagasaki University) of this international virtual learning class were situated in Kyushu-Sangyo University (KSU) in Fukuoka, Japan. The reason why 
was inputted into the sender machine of the DVTS. It was then sent to the receiver via the gigabit network.

Table 1: Questionnaire Sentences

\begin{tabular}{|c|l|}
\hline ID & \multicolumn{1}{|c|}{ Sentences } \\
\hline S01 & Japan learns from foreign countries. \\
\hline S02 & $\begin{array}{l}\text { Japanese people should be more hospitable to } \\
\text { foreigners. }\end{array}$ \\
\hline S03 & $\begin{array}{l}\text { Other countries' problems are unrealized to } \\
\text { us. }\end{array}$ \\
\hline S04 & $\begin{array}{l}\text { Taking in foreign culture has a positive } \\
\text { impact on Japan. }\end{array}$ \\
\hline S05 & It is important to consider one's own country. \\
\hline S06 & $\begin{array}{l}\text { If I see an old temple and an old private house } \\
\text { in Japan, I feel familiar. }\end{array}$ \\
\hline S07 & I am proud of being Japanese. \\
\hline S08 & I seldom have attachment to my country. \\
\hline S09 & $\begin{array}{l}\text { It is difficult to consider things from the } \\
\text { viewpoint of a foreign person. }\end{array}$ \\
\hline S10 & $\begin{array}{l}\text { When determining something, it is important } \\
\text { to take the viewpoint of someone with an } \\
\text { opposite opinion. }\end{array}$ \\
\hline S11 & $\begin{array}{l}\text { In order to understand others well, I must see } \\
\text { things as they do. }\end{array}$ \\
\hline S12 & $\begin{array}{l}\text { If I think that my judgment is right, I will not } \\
\text { consider other's opinion. }\end{array}$ \\
\hline S13 & South Korea is like a distant country. \\
\hline S14 & I want to study Korean. \\
\hline S15 & $\begin{array}{l}\text { I want to make friends with South Korean } \\
\text { students. }\end{array}$ \\
\hline S16 & $\begin{array}{l}\text { I want to know South Korean history, culture, } \\
\text { life, etc. }\end{array}$ \\
\hline S17 & $\begin{array}{l}\text { I want to talk with South Korean students. } \\
\text { S18 }\end{array}$ \\
$\begin{array}{l}\text { South Korean students are a different race } \\
\text { from us. }\end{array}$ \\
\hline S19 & $\begin{array}{l}\text { Japan and South Korea's schools and way of } \\
\text { life are like. }\end{array}$ \\
\hline S20 & $\begin{array}{l}\text { I don't characterize South Koreans as } \\
\text { foreigners. }\end{array}$ \\
\hline
\end{tabular}

Although Japan and South Korea are neighboring country, communication is difficult because of the language barrier. Therefore, the automatic translation chatting system developed by Kyushu Electric Power Co, Inc. was applied and an interpreter corrected inaccuracies.

\subsection{Content}

46 Japanese students belonging to the attached school of Nagasaki University (NU) and 30 South
Korean students from the attached school of Chonnam National University (ChNU) participated in the international virtual learning class and discussed energy problem in the world at $19^{\text {th }}$ of February in 2004. The day before the class, they had a meeting to introduce themselves each other.

The objective of the class was to develop their motivation and creation through international collaboration to discuss the future energy sources and application. The process of the class was as follows; (1) the data of fossil fuel consumption was shown to students and they calculated the problems of power generation, (2) the energy problems were explored by students using the data of energy composition ratio in some countries, (3) the relation between coal and electric power was discussed, (4) students suggested some new energies through international collaboration.

\subsection{Investigation}

The first investigation had done in Nov in 2003 was called "before" investigation, and the second investigation had done in Feb in 2004 was called “after' investigation.

Table 1 shows sentences from the questionnaire. In order to reveal the effects of the class, the questionnaire was composed of five categories; Consciousness to Foreign Countries, Nationality, Acquisition of View Point, Motivation, Recognition to the partner country.

Results were compared in order to investigate the effects of the international virtual learning class. The experimental design was a $2 \times 2$ mixed factorial. The two independent variables were "country" (Japan or South Korea) and "change" (pre-post-control), "Country" was between subjective variable and "change" was within subjective variable.

\section{Results}

\subsection{Changes of student's attitude}

38 Japanese students and 25 South Korean students made valid and complete responses to the questionnaire before and after the class. The mean scores were calculated on the total number of 63 students on a scale of $1-5$, with 1 representing "strongly disagree" and 5 indicating "strongly agree."

Figure 2 shows the mean score of each sentence in the questionnaires. Japanese students' score is shown in the left side graph, and South Korean students' score is shown in the right. The results were tested using mixed two-way analysis of variance (ANOVA). 
The results of the ANOVA are also shown in Figure 2. In this figure, the symbols between two graphs represent significant difference of "country" factor. Additionally, the symbols included in the graph area

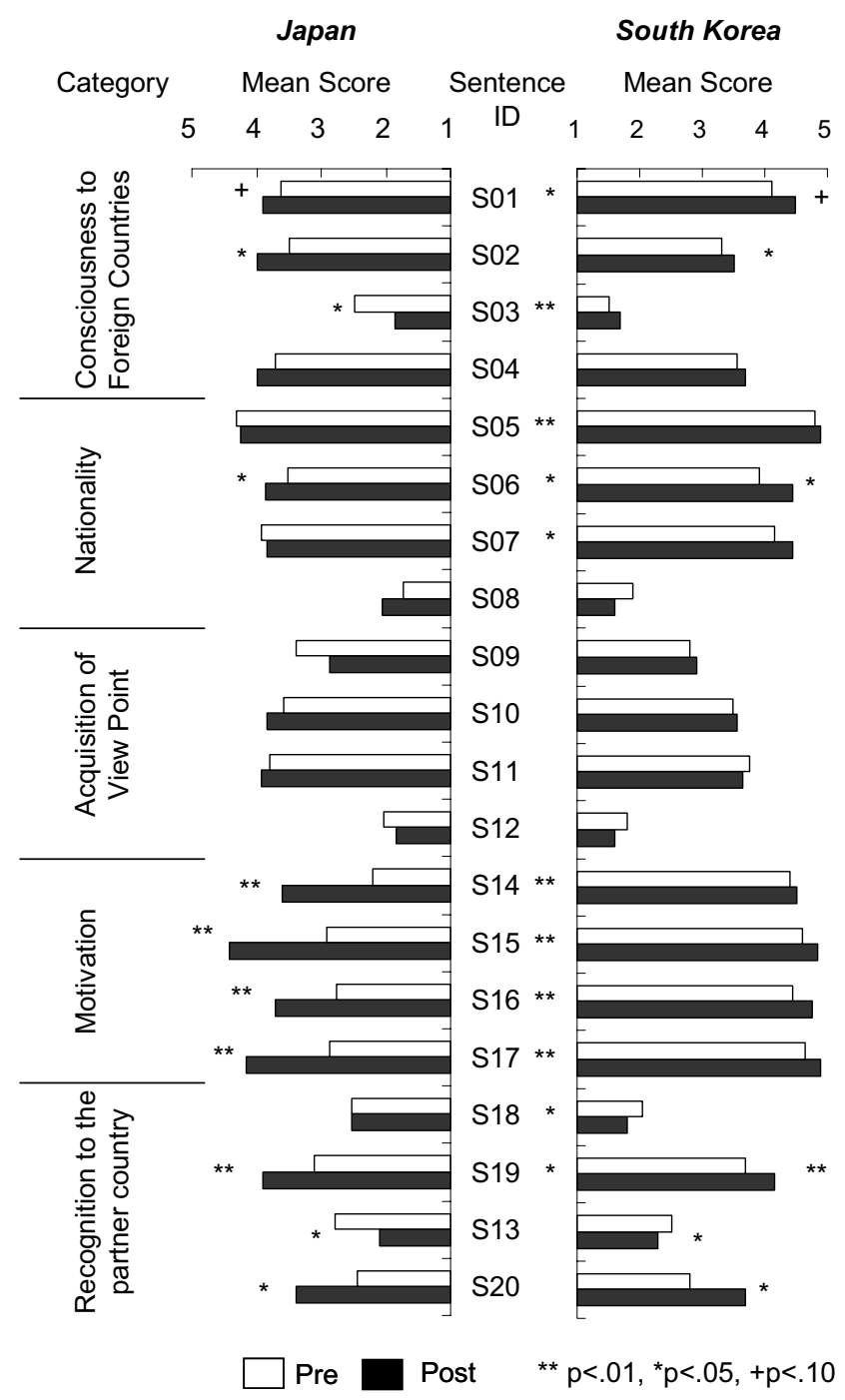

Figure 2: Results of ANOVA

represent significant difference of "change" factor.

Consciousness to Foreign Countries: The result of the ANOVA on S01 showed a significant main effect of country $(\mathrm{F}(1,61)=6.49, \mathrm{p}<.05)$, and no significant differences in the "change" factor. S02 showed no significant main effect of "country" factor, and a significant main effect of "change" factor $(\mathrm{F}(1,61)=4.19, \mathrm{p}<.05)$. On S03, there was a significant interaction $(\mathrm{F}(1,61)=6.70, \mathrm{p}<.05)$, so, the result was tested using simple main effect analysis. It showed a significant difference between Japan and South Korea at before the virtual learning class, and a significant difference before and after the score of Japan $(\mathrm{MSe}=.66,5 \%$ significant level). It showed no significant differences were observed in S04. Consequently, the results revealed that Japanese students had changed their attitude by the end of the class as they began to think that a problem in a foreign country was related to them.

Nationality: The result of the ANOVA on S05 showed a significant main effect of "country" factor $(F(1,61)=12.07, p<.01)$, and no significant differences in the "change" factor. S06 showed a significant main effect of "country" factor $(\mathrm{F}(1,61)=4.96, \mathrm{p}<.05)$, and also a significant main effect of "change" factor $(F(1,61)=6.92, p<.05)$. S07 showed a significant main effect of "country" factor $(\mathrm{F}(1,61)=4.05, \mathrm{p}<.05)$, and no significant differences in the "change" factor. It showed no significant differences were observed in S08. Consequently, South Korean students had higher consciousness of nationality than Japanese students.

Acquisition of View Point: The result of the ANOVA showed no significant differences were observed in S09-S12. Therefore, the results revealed that students did not acquire foreign perspective from this class alone.

Motivation: The results of the ANOVA on S14S17 showed significant interactions $(F(1,61)=22.74$, $\mathrm{p}<.01 ; \quad \mathrm{F}(1,61)=15.20, \mathrm{p}<.01 ; \quad \mathrm{F}(1,61)=4.68, \mathrm{p}<.05 ;$ $\mathrm{F}(1,61)=7.77, \mathrm{p}<.01)$. The results were tested using simple main effect analysis. It showed significant differences between Japan and South Korea, and significant differences before and after the score of Japan $(\mathrm{MSe}=.54 ; \mathrm{MSe}=.79 ; \mathrm{MSe}=.63 ; \mathrm{MSe}=.1 .07,5 \%$ significant level). It is for this reason of interactions that the South Korean students were seen to have a high motivation before the class, so "ceiling effect" was appeared to each sentence of this category. Consequently, the results revealed that South Korean students were seen to have higher motivation than Japanese students, and the motivation of Japanese students was increased after the class.

Recognition to the partner country: The result of the ANOVA on S18 showed a significant main effect of "country" factor $(F(1,61)=6.59, \mathrm{p}<.05)$, and no significant differences in the "change" factor. S19 showed a significant main effect of "country" factor $(\mathrm{F}(1,61)=5.44, \mathrm{p}<.05)$, and also showed a significant main effect of "change" factor $(\mathrm{F}(1,61)=30.53, \mathrm{p}<.01)$. The results on $\mathrm{S} 13$ and $\mathrm{S} 20$ showed no significant main effect of "country" factor, and significant main effects of "change" factor $(\mathrm{F}(1,61)=5.58, \mathrm{p}<.05$; $\mathrm{F}(1,61)=22.83, \mathrm{p}<.01)$. Consequently, both sets of 
students recognized that Japan and South Korea were neighboring countries, and they observed the linguistic barrier that exists between them.

\section{Conclusion}

The purpose of this study was to implement an international virtual learning class which regarding energy problem using cross-border infrastructure, and to reveal the changes of student's attitude before and after the class.

According to the comparative analysis, the effects of the virtual learning class were revealed as follows;

- Japanese students had changed their attitude by the end of the class as they began to think that a problem in a foreign country was related to them.

- South Korean students had higher consciousness of nationality than Japanese students.

- Students did not acquire foreign perspective from this class alone.

- South Korean students were seen to have higher motivation than Japanese students, and the motivation of Japanese students was increased after the class.

- Both sets of students recognized that Japan and South Korea were neighboring countries, and they observed the linguistic barrier that exists between them.

These results reveal that an international virtual learning class may develop and enhance student's awareness of humanity and the world around them. We suggest that international virtual learning class in elementary or middle schools is one of the solutions for the global understandings. Future implementation will depend on growth and sustenance of the international relationship for a prolonged period.

\section{Acknowledgement}

We wish to express our gratitude to Prof. Koji Okamura of Kyushu University and QGPOP (Kyushu GigaPOP Project) members, Genkai - Project members. We also would like to thank TAO (Telecommunication Advancement Organization of Japan) for our use of JGN (Japan Gigabit Network). In Addition, We would like to thank head teacher, Mr. Nishiyama and Mr. Okano schoolteacher at the junior high school attached Nagasaki University, and also, head teacher, Mr. Yoon, Mr. kan, and Mr.Son schoolteacher at the junior high school attached
Chonnam National University. We are indebted to $\mathrm{Mr}$. of Kyushu Electric Power Co, Inc.

This research was supported in part by a grant from e!Project by Ministry of Public Management, Home Affairs, Posts and Telecommunications and JSPS (Japan Society for the Promotion of Science) Core University Programs in ASIA.

\section{References}

[1] Morita, Y., Fujiki, T., Nakamura, C., Kamizono, K. “A moral education in a virtual classroom adopted multipoint telecommunication with tele-group activity using cellular phones", Proceedings of International workshop of Interactive Computer Aided Learning, Villach/Austria, 2002.

[2] Ogawa, A., Kobayashi, K., Sugiura, K., Nakamura, O., Murai, J. "Design and Implementation of DV based Video over RTP”, http://www.sfc.wide.ad.jp/DVTS/ pv2000/

[3] Morita, Y., Fujiki, T., "Implementation of Virtual learning classroom Visitations and Distance Evaluation Meetings: A Comparison between DVTS and mpeg2ts", Proceedings of the 2nd IASTED International Conference on Communication, Internet, \& Information Technology, Scottsdale /USA, 2003, pp.509-514.

[4] Watanabe, K., Sumi, N., Aimori, T., Otani, M., "An Implementation of a Remote Blackboard Presenter System for Remote Lessons in Conventional Blackboard Based Style with Rich Media Environment", Proceedings of International Conference on Computers in Education, Auckland/NZ, 2002, pp.713-714. 